\title{
O BALANÇO DE UMA DÉCADA DA PROMULGAÇÃO DAS DIRETRIZES CURRICULARES NACIONAIS PARA A EDUCAÇÃO INFANTIL NA PRODUÇÃO ACADÊMICA BRASILEIRA
}

\author{
Sinara Almeida da Costa ${ }^{1}$ \\ Rosimeire Costa de Andrade Cruz ${ }^{2}$
}

\begin{abstract}
RESUMO
O presente artigo tem como objetivo apresentar um balanço do que foi produzido em trabalhos científicos na área de Educação Infantil na primeira década após a promulgação das Diretrizes Curriculares Nacionais para a Educação Infantil - DCNEl (BRASIL, 2009). Seu principal aporte teórico é Leontiev (1978), que defende a ideia que é através da educação que o homem torna-se humano em sua essência. Resulta de uma pesquisa do tipo "Estado da Arte" que, através de uma metodologia inventariante e descritiva, fez o levantamento das produções acadêmicas sobre as DCNEI (BRASIL, 2009) no período de 2010 a 2020 em três plataformas eletrônicas: Catálogo de Teses e Dissertações da Coordenação de Aperfeiçoamento de Pessoal de Nível Superior - CAPES, Google Acadêmico e ResearchGate. Seus resultados apontam os temas de maior destaque nas pesquisas e que envolvem a compreensão de currículo em sua episteme, perpassando por reflexões acerca das teorias, concepções e conceitos que o compõem. Em contrapartida, assuntos como o brincar, as interações, a educação para as relações étnico-raciais, a avaliação e a prática com bebês, fundamentais para a efetivação de um currículo que considere a criança como centro, ainda são pouco explorados ou sequer aparecem entre os temas focalizados. Além disso, evidenciam inúmeros desafios que precisam ser enfrentados pela comunidade acadêmico-científica em relação ao currículo na Educação Infantil e suas especificidades, o que possibilita a ampliação dos debates sobre o tema.
\end{abstract}

Palavras-chave: Diretrizes Curriculares Nacionais para a Educação Infantil. Estado da Arte. Currículo.

\footnotetext{
1 Doutora pela Faculdade de Educação da Universidade Federal do Ceará- FACED/UFC; Professora Associada I do Instituto de Ciências da Educação da Universidade Federal do Oeste do Pará- UFOPA- Brasil; Professora Permanente do Programa de Pós-graduação em Educação da UFOPA; Líder do grupo de Estudos e Pesquisas em Edcuação Infantil- GEPEIUFOPA. Orcid iD: htpps://orcid.org/0000-00017676-5040. E-mail: sinaraacs@hotmail.com

2 Doutora pela Faculdade de Educação da Universidade Federal do Ceará - FACED/UFC; Professora Associada II da FACED/UFC - Brasil; Professora Permanente do Programa de Pósgraduação em Educação Brasileira da FACED/UFC; Coordenadora do Grupo de Pesquisa Propostas pedagógicas e formação de professores na Educação Infantil; Orcid iD: https://orcid.org/0000-0003-2532-010X.E-mail: rosimeireca@yahoo.com.br
} 


\title{
THE BALANCE OF A DECADE IN THE PROMULGATION OF NATIONAL CURRICULUM GUIDELINES FOR EARLY CHILDHOOD EDUCATION IN BRAZILIAN \\ ACADEMIC PRODUCTION
}

\begin{abstract}
This article aims to present a balance of what was produced in scientific works in the area of Early Childhood Education in the first decade after the promulgation of the National Curriculum Guidelines for Early Childhood Education - DCNEI (BRASIL, 2009). His main theoretical contribution is Leontiev (1978), who defends the idea that it is through education that man becomes human in essence. It results from a "State of the Art" type research that, through an inventory and descriptive methodology, surveyed academic productions on DCNEI (BRASIL, 2009) in the period from 2010 to 2020 on three electronic platforms: Thesis Catalog and Dissertations from the Coordination for the Improvement of Higher Education Personnel - CAPES, Academic Google and ResearchGate. Its results point out the most prominent themes in the researches and which involve the understanding of the curriculum in its episteme, passing through reflections on the theories, conceptions and concepts that compose it. On the other hand, issues such as playing, assessment and practice with babies, which are fundamental for the implementation of a curriculum that considers the child as the center, are still little explored. In addition, they highlight numerous challenges that need to be faced by the academic-scientific community in relation to the curriculum in Early Childhood Education and its specificities, which enables the expansion of debates on the subject.
\end{abstract}

Keywords: Diretrizes Curriculares Nacionais para a Educação Infantil. State of art. Resume.

\section{EL EQUILIBRIO DE UNA DÉCADA EN LA APLICACIÓN DE LAS DIRECTRICES DEL CURRÍCULO NACIONAL PARA LA EDUCACIÓN DE LA PRIMERA INFANCIA EN LA PRODUCCIÓN ACADÉMICA BRASILEÑA}

\section{RESUMEN}

El presente artículo tiene como objetivo presentar un balance de lo que fue producido en trabajos científicos en el área de Educación Infantil en la primera década después de la promulgación de las Directrices Curriculares Nacionales para la Educación Infantil - DCNEI (BRASIL, 2009). Su principal aporte teórico es Leontiev (1978), que defiende la idea que es a través de la educación que el hombre se vuelve humano en su esencia. Resulta de una investigación del tipo "Estado del Arte" que, a través de una metodología inventariante y descriptivo, hizo el levantamiento de las producciones académicas sobre las DCNEI (BRASIL, 2009) en el período de 2010 a 2020 en tres plataformas electrónicas: Catálogo de Tesis y Disertaciones de la Coordinación de Perfeccionamiento de Personal de Nivel Superior - CAPES, Google Académico y ResearchGate. Sus resultados apuntan los temas de mayor destaque en las investigaciones y que envuelven la comprensión de currículo en su episteme, perpassando por reflexiones acerca de las teorías, concepciones y conceptos que lo componen. En cambio, temas como el juego, la evaluación y la práctica con bebés, fundamentales para la realización de un currículo que considere al niño como centro, aún son poco explotados. Además, 
evidencian numerosos desafíos que necesitan ser enfrentados por la comunidad académico-científica en relación al currículo en la Educación Infantil y sus especificidades, lo que posibilita la ampliación de los debates sobre el tema.

Palabras clave: Diretrizes Curriculares Nacionais para a Educação Infantil. Estado del arte. Reanudar.

\section{INTRODUÇÃO}

O presente artigo tem como objetivo apresentar um balanço do que foi produzido em trabalhos científicos na área de Educação Infantil na primeira década após a promulgação das Diretrizes Curriculares Nacionais para a Educação Infantil - DCNEI (BRASIL, 2009). Tal propósito leva em consideração o contexto político e pedagógico que desencadeou a necessidade de revisão do Referencial Curricular Nacional para a Educação Infantil (BRASIL, 1998) e da Resolução CNE/CEB n. ${ }^{\circ}$ 1, de 7 de abril de 1999 (BRASIL, 1999), e que culminou na atual Base Nacional Comum Curricular BNCC (BRASIL, 2017).

Nesse ínterim, as DCNEI (BRASIL, 2009) são elaboradas com a finalidade de orientar "a organização de propostas pedagógicas na Educação Infantil" (Art. $1^{\circ}$ ). Tal dispositivo, de caráter mandatório, cria a possibilidade de planejamento e realização de um trabalho pedagógico que tenha a criança como centro do processo educativo e as interações e brincadeiras como eixos das práxis.

Tendo em vista que no Brasil estamos vivendo um momento de retrocessos políticos importantes - como a ameaça à democracia conquistada às custas de muitas lutas e ao tombamento de muitas vidas que terão consequências graves em todas as áreas, não podemos deixar de considerar e refletir sobre as repercussões das DCNEI (BRASIL, 2009) no cenário nacional procurando compreender os meandros percorridos no âmbito acadêmico até aqui. Vale considerar que, via de regra, esse campo resulta de pesquisas em contextos reais, portanto, também indica o impacto 
desse documento legal em várias realidades institucionais que cuidam/educam ${ }^{3}$ crianças de 0 a 5 anos e 11 meses de idade.

$\mathrm{Na}$ leitura que fazemos das publicações identificadas nesse levantamento referente a essa primeira década pós DCNEI (BRASIL, 2009), consideramos a influência das ideias de Leontiev (1978). Segundo esse teórico, para tornar suas as aquisições do desenvolvimento histórico das aptidões humanas, o homem deve entrar em relação com os fenômenos do mundo circundante através doutros homens, num processo de comunicação com eles. Assim, é através da educação que o homem tornase humano em sua essência.

A escola, como contexto educativo formal, tem responsabilidade nesse processo, devendo contribuir de maneira positiva no desenvolvimento da inteligência e personalidade dos estudantes. Em comparação com as finalidades das demais etapas da educação básica, as instituições de Educação Infantil, que tem como público "meninos e meninas, recém chegados ao mundo, [que terão, gradativamente, de dar] conta de um entorno repleto de situações a serem compreendidas e tomadas para si no exercício de se tornar humano" (FOCHI, 2015, p.48), ou seja, bebês, crianças bem pequenas e crianças pequenas ${ }^{4}$, que estão em processo intenso de aprendizagem e desenvolvimento, tal encargo torna-se ainda maior.

Nesse sentido, o balanço, aqui apresentado, dos impactos na produção acadêmica de uma década da promulgação das DCNEI (BRASIL, 2009) se propõe a responder a seguinte questão: o que ocorreu na esfera da pesquisa na área de Educação Infantil durante a primeira década de promulgação das DCNEl? Desta pergunta central, outras se fazem

\footnotetext{
3 A opção pela justaposição "cuidam/educam" e "cuidado/educação" inspira-se em Ribeiro (2020, p.19), que também adota essa escrita "com o intuito de reforçar que [cuidado/educação] se tratam de ações profundamente entrelaçadas. Compreende-se, ainda, que a definição de "binômio" com o emprego das duas palavras separadamente ("cuidar" e "educar"; "cuidado" e "educação") denota uma compreensão de que são práticas distintas que podem ou não estar vinculadas".

${ }^{4}$ Essa nomenclatura baseia-se na A BNCC (BRASIL, 2017) que usa a palavra "bebês" para referir-se às crianças de 0 a 18 meses; "crianças bem pequenas" para se reportar aquelas que têm entre- 18 meses a 3 anos de idade; e "crianças pequenas" para alude àquelas que têm de 4 a 5 anos.
} 
pertinentes: quais os temas de maior atenção nas pesquisas desenvolvidas nesse período? O que eles atestam? Qual o período de maior interesse acadêmico científico nesses dez anos? Qual o cenário político desse período?

Tais questionamentos não ocorrem de forma arbitrária, mas, sim, daquilo que entendemos que seja a busca pela cientificidade do saber e, dessa mesma forma, o sentido histórico, social, cultural e político de sua produção.

Essa compreensão nos induz a estruturar a exposição em cinco pontos: o primeiro, que aqui trazemos, introduz o tema, apresenta os propósitos do artigo e o seu foco; o segundo trata do contexto político dos embates legais que marcaram a conjuntura da década; o terceiro apresenta o percurso metodológico empreendido no levantamento; o quarto, traçado tendo como cenário a conjuntura do decênio, apresenta e tece reflexões sobre o que foi produzido nessa década a partir de pesquisas acadêmico-científicas e ensaios teóricos; e, por fim, o quinto, aponta algumas reflexões candentes que nos interpelam como pesquisadoras e militantes na área de Educação Infantil.

Percebe-se, assim, que a realização do balanço supradito possibilita uma espécie de "estado da arte" inicial do que foi produzido sobre e o que ocorreu na área de Educação Infantil durante o decênio eleito para a pesquisa, bem como um roteiro indicativo que nos pode possibilitar uma leitura histórica da conjuntura vigente no referido período.

\section{O CONTEXTO POLÍtICO E A NOVA DEFINIÇÃO DE CURRÍCULO A PARTIR DAS DCNEI (BRASIL, 2009)}

Compreender o contexto histórico de estruturação da política de El brasileira é condição para o debate sobre a necessidade de reestruturação curricular das creches e pré-escolas.

Segundo Rosemberg (2000, p.136), o Brasil passou a se preocupar com a melhoria da qualidade de vida e, consequentemente, com a educação das crianças somente a partir do 
impacto de novas ideias sobre Educação Infantil veiculadas pelos movimentos sociais das décadas de 1970 e 1980 (o movimento das mulheres e o movimento pelos direitos das crianças e dos adolescentes).

Juridicamente, a sociedade brasileira passou a reconhecer as crianças como cidadãos de direitos, entre os quais, o direito à Educação, a partir da realização, em 1975, pelo Ministério da Educação (MEC), do primeiro Diagnóstico Nacional da Educação Pré-escolar. Após quatro anos, outra ação deste porte foi posta em prática, sendo 1979 declarado o Ano Internacional da Criança. Foi com a aprovação da Constituição Federal (BRASIL, 1988), no entanto, e com a regulamentação de alguns de seus artigos, mediante o Estatuto da Criança e do Adolescente - ECA (BRASIL, 1991) e a Lei de Diretrizes e Bases da Educação Nacional - LDB (BRASIL, 1996), que se efetivou maior atenção às crianças de zero a seis anos. Com isso, a Educação passou a ser, além de um direito fundamental da criança, uma garantia constitucional (KRAMER, 2005).

A promulgação da Constituição Federal em vigor (BRASIL, 1988) delega ao Poder Público uma responsabilidade nunca antes assumida: o atendimento gratuito em instituições de Educação Infantil às crianças de zero a cinco anos como parte de seu dever com a educação.

O ECA (BRASIL, 1991) prevê igualdade de condições para o acesso e permanência das crianças e adolescentes na escola, destacando sua condição de sujeitos de direitos, que devem ser tratados com prioridade absoluta pelo Poder Público.

A LDB (BRASIL, 1996) também trouxe inúmeras contribuições à área, dentre as quais: a Educação Infantil como primeira etapa da Educação Básica, direito da criança, dever do Estado, opção da família ${ }^{5}$, vinculada aos sistemas de ensino, e a avaliação sem o objetivo de promoção para o Ensino Fundamental.

\footnotetext{
${ }^{5}$ Com a aprovação da Lei $n^{\circ} 12.796$, de 4 de abril de 2013, que alterou a redação da LDB vigente, a educação básica passou a ser obreigatóra dos 4 (quatro) aos 17 (dezessete) anos de idade (BRASIL, 2013). Assim, a matrícula na creche passou a ser opcional para as famílias e obritória a oferta pelo poder público; e a matrícula e a oferta da pré-escola passou a ser obtrigatória.
} 
Acompanhando o reconhecimento da Educação Infantil como etapa específica da Educação Básica e levando em consideração suas especificidades pedagógicas cada vez mais explícitas, em 1998 foi lançado o Referencial Curricular Nacional para a Educação Infantil (BRASIL, 1998) como uma primeira tentativa de adequar os novos objetivos educacionais às propostas curriculares previstas para as creches e pré-escolas. Tal documento, passou por um processo de revisão e ampliação ao longo de dez anos, sendo reeditado através da Resolução N5 do Conselho Nacional de Educação - CNE no ano de 2009.

Entre as principais definições presentes nesse documento mandatório, estão o conceito de criança (tida como sujeito histórico e de direitos, centro do planejamento curricular), a concepção de Educação Infantil (reconhecida como formal e a ser realizada em espaços institucionais não domésticos, públicos ou privados, que educam/cuidam crianças de 0 a 5 anos de idade no período diurno, em jornada integral ou parcial e currículo (concebido como um conjunto de práticas que buscam articular as experiências e os saberes das crianças com os conhecimentos que fazem parte do patrimônio humano); e as interações e brincadeiras como os eixos norteadores das práticas pedagógicas desenvolvidas com e para as crianças.

Ao se tratar de práticas pedagógicas é importante compreender que estas não são neutras. Sempre têm orientações (por mais oculta que possam parecer) que as guiam e são influenciadas pela concepção de criança e de Educação Infantil dos professores.

É um desafio fazer com que o currículo seja concebido como o projeto formativo integrado que se desenvolve durante toda a escolaridade (ZABALZA, 1998, p. 13). O currículo deve integralizar a vida na escola e a escola na vida, pois não há educação fora da vida (VIGOTSKI, 2010). Segundo as DCNEI (BRASIL, 2009), deve haver diálogo entre as experiências e saberes de vida da criança e os conhecimentos que a humanidade construiv e acumulou durante sua história. 
A definição de currículo contida nesse documento normativo põe o foco na ação mediadora da instituição de Educação infantil como articuladora das experiências e saberes das crianças e os conhecimentos que circulam na cultura mais ampla. Tal definição inaugura, então, um importante período na área, que pode, de modo inovador, avaliar e aperfeiçoar as práticas vividas pelas crianças nas unidades de Educação Infantil (OLIVEIRA, 2010, p.4).

No ano de 2013 é promulgada a Lei $N^{\circ}$ 12.796, que, entre outras provisões, insere a Educação infantil na definição de uma Base Nacional Comum Curricular para a Educação Básica (BRASIL, 2013), intensificando ainda mais os debates sobre as precauções ao se pensar um currículo que leve em consideração as características e necessidades dos bebês, das crianças bem pequenas e das crianças pequenas. Apesar de inserida em uma proposta comum nacional para a Educação Básica, às custas de muitas lutas, especialmente, dos movimentos sociais e universidades, a Educação Infantil manteve algumas de suas especificidades curriculares, uma vez que não se define por conteúdos ou disciplinas, mas por Campos de Experiências que precisam se ajustar aos princípios, às condições e aos objetivos expressos nas DCNEI (BRASIL, 2009).

\section{PERCURSO METODOLÓGICO}

Trata-se de uma pesquisa do tipo "Estado da Arte" cuja intenção é de, por meio de uma metodologia inventariante e descritiva, "mapear e discutir uma certa produção acadêmica em diferentes campos do conhecimento, tentando responder que aspectos e dimensões vêm sendo destacados e privilegiados em diferentes épocas e lugares" (FERREIRA, 2002, p.258).

Adotar essa forma de fazer pesquisa alicerça-se no argumento de Romanowsk e Teodora Ens (2006, p.38) de que:

faltam estudos que realizem um balanço e encaminhem para a necessidade de um mapeamento que desvende e examine $o$ conhecimento já elaborado e apontem os enfoques, os temas mais pesquisados e as lacunas existentes. 
De igual maneira, André (2009, p.43) complementa que este tipo de pesquisa é revelador dos "temas que permanecem ao longo do tempo, assim como os que esmaecem, os que despontam promissores e os que ficam totalmente esquecidos" pela academia.

Ao caracterizar essa modalidade de investigação, Romanowsk e Teodora Ens (2006) elencam alguns procedimentos adotados que também estão presentes neste levantamento das produções acadêmicas sobre as DCNEI (BRASIL, 2009) publicadas no decênio 2010 a 2020, dentre eles, não se restringir à identificação da produção, mas analisá-las; indicar as lacunas de disseminação do conhecimento resultante dos trabalhos mapeados; e examinar os temas mais e menos presentes nas investigações bem como os objetivos a eles relacionados.

Fazer um levantamento de publicações de pesquisas no formato eletrônico, o que vem aumentando, especialmente, desde a década de 2000, conforme aponta Caregnato (2011, p.72), "têm ampliado a oportunidade de se obter uma visão mais complexa e pormenorizada das redes formadas pelas comunidades científicas das diferentes áreas". Por outro lado, é importante ter clareza de que por mais abrangência que pareça ter, nenhuma

\footnotetext{
base de dado apresenta cobertura completa da publicação científica mundial, o que aponta para a necessidade de seleção das bases de dados mais adequadas para as condições da análise desejadas, incluindo abrangência geográfica, área do conhecimento e período do estudo a ser feito. (FARIA et al p.8).
}

Considerando a incompletude comum aos bancos de dados on-line, os autores suprarreferidos recomendam "a utilização de mais de uma base de dados [...] para que, na falta de uma visão baseada na totalidade das publicações, possam ser construídas mais visões parciais para comparação e complementação" (FARIA et al p.8). Nesta perspectiva, a pesquisa foi realizada nas seguintes plataformas eletrônicas: Catálogo de Teses e Dissertações da Coordenação de Aperfeiçoamento de Pessoal de Nível Superior - CAPES, Google Acadêmico e ResearchGate, no período de maio a julho de 2021. O critério para inclusão do trabalho localizado foi aparecer 
no título a combinação dos seguintes descritores: "Diretrizes Curriculares Nacionais para a Educação Infantil" e "creche"; "Diretrizes Curriculares Nacionais para a Educação Infantil" e "pré-escola".

Tanto no Catálogo de Teses e Dissertações da Coordenação de Aperfeiçoamento de Pessoal de Nível Superior - CAPES como no Google Acadêmico o tipo de busca adotado foi o simples. No site ResearchGate a busca, também simples, foi realizada no formato "não logado"

A adoção do recorte temporal de 2010 a 2020 vincula-se tanto ao primeiro ano após a promulgação das DCNEI (BRASIL, 2009) - 2010 - como também ao primeiro ano após a implantação da BNCC (BRASIL, 2017) 2020. Tratam-se de dois documentos orientadores e mandatórios relacionados ao currículo na Educação Infantil, tema ainda não consensual entre os pesquisadores da área.

\section{O QUE REVELAM AS PESQUISAS SOBRE AS DCNEI (BRASIL, 2009) APÓS UMA DÉCADA DE SUA PROMULGAÇÃO?}

Incluindo os estudos localizados em mais de uma plataforma consultada, o quantitativo de trabalhos publicado por ano encontra-se distribuído conforme apresentado no Quadro 1 a seguir.

Quadro 1 - Trabalhos publicados, por ano, que versam sobre as DCNEl (BRASIL, 2009) no decénio de 2010 a 2020

\begin{tabular}{|c|c|c|c|c|c|}
\hline \multirow{3}{*}{$\begin{array}{c}\text { Ano de } \\
\text { publica- } \\
\text { ção }\end{array}$} & \multicolumn{4}{|c|}{ Banco de dados } & \multirow{3}{*}{$\begin{array}{c}\text { Quantidade de } \\
\text { pesquisas sem } \\
\text { exclusão dos } \\
\text { trabalhos } \\
\text { duplicados }\end{array}$} \\
\hline & \multicolumn{2}{|c|}{ Google Acadêmico } & \multirow{2}{*}{$\begin{array}{l}\text { Catálogo } \\
\text { de Teses e } \\
\text { Dissertaçõ } \\
\text { es - CAPES }\end{array}$} & \multirow{2}{*}{ ResearchGate } & \\
\hline & $\begin{array}{c}\text { Com os } \\
\text { duplicados }\end{array}$ & $\begin{array}{c}\text { Sem os } \\
\text { duplicados }\end{array}$ & & & \\
\hline 2010 & - & - & 01 & 01 & 02 \\
\hline 2011 & - & - & - & - & - \\
\hline 2012 & - & - & - & - & - \\
\hline $2013^{*}$ & 01 & 01 & 03 & - & 04 \\
\hline $2014^{*}$ & 01 & 01 & - & 01 & 02 \\
\hline
\end{tabular}




\begin{tabular}{|c|c|c|c|c|c|}
\hline & & & & & - \\
\hline $2015^{*}$ & 01 & 01 & - & 02 & 03 \\
\hline $2016^{*}$ & 01 & 01 & - & 01 & 07 \\
\hline $2017^{*}$ & 03 & 03 & 03 & - & - \\
\hline 2018 & - & - & - & 02 & 04 \\
\hline 2019 & - & - & 02 & 02 & 28 \\
\hline $2020^{*}$ & 02 & 02 & 01 & 09 & $\mathbf{2 1}$ \\
\hline Total & 09 & 09 & 10 & & 05 \\
\hline
\end{tabular}

Fonte: Elaboração das autoras, 2021.

* Anos em que foram localizados trabalhos duplicados

** Com exclusão dos 09 trabalhos duplicados

De acordo com o Quadro 1, percebe-se que, embora existam variações na quantidade dos estudos produzidos por ano, há um discreto crescimento no período de 2010 a 2013; nos biênios 2016 a 2017 (período de maior elevação) e 2019 a 2020 na quantidade das publicações sobre as DCNEI (BRASIL, 2009). Todavia, há um relativo decréscimo da quantidade de pesquisas nos seguintes intervalos de tempo: 2013 a 2015 e 2017 a 2019 (triênio de superior declínio). Chama a atenção o fato de não ter sido identificado nenhum trabalho em 2011, 2012 e 2018. O Gráfico 1, a seguir, evidencia esse movimento de ampliação e declínio no conjunto de investigações decorrente desse levantamento:

Gráfico 1 - Variação da produção acadêmica sobre as DCNEI (BRASIL, 2009) na década de 2009 - 2020

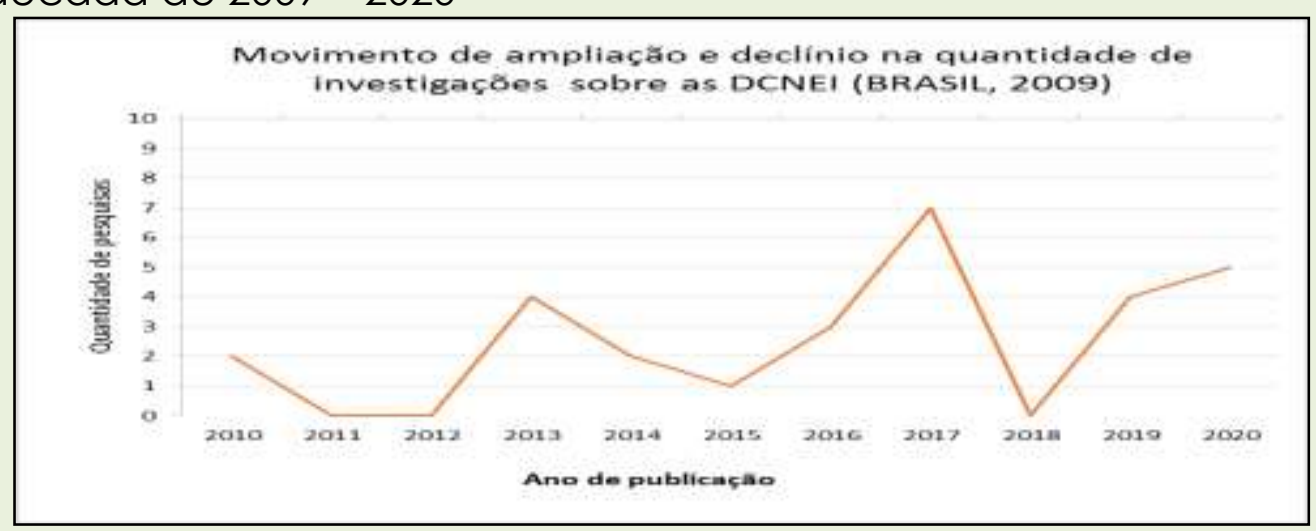

Fonte: Elaboração das autoras, 2021. 
Na perspectiva de Santos, Barroso e Nascimento (2020, p.359), a oscilação na quantidade de publicação nesse decênio reflete "momentos de recuo e avanço da compreensão e aceitação (ou não) da ideia de um currículo para creches e pré-escolas". Acrescente-se a isso "a defasagem entre a norma e sua efetiva implementação no cotidiano das instituições" (LOPES, 2011 , p.7).

De fato, não existe uma correspondência entre os avanços na legislação e o que parece ter sido privilegiado nas publicações localizadas nesse levantamento. Ademais, a aprovação das DCNEl (2009), paradoxalmente, representa "um momento importante de fortalecimento e consolidação dessa etapa [Educação Infantil] como a primeira da educação básica, também desvela alguns temas difíceis para a área" (CARVALHO; FOCHI, 2017, p.15).

A necessidade de um currículo para a educação formal de bebês, crianças bem pequenas e crianças pequenas é emblemática dos dissensos persistentes tanto no âmbito acadêmico como institucional onde se pesquisa e se efetiva essa primeira etapa da educação básica, mesmo que a compreensão do que seja currículo presente nesse documento normativo diferencie-se radicalmente da perspectiva de disciplina escolar. Outrossim, é concebido como "um conjunto de práticas que possibilita aos professores elaborarem seus planejamentos com base nas experiências e nos interesses das crianças, [articulando-os] com os conhecimentos socialmente produzidos" (CARVALHO; FOCHI, 2017, p.27), com vias à promoção do desenvolvimento integral de crianças de 0 a 5 anos de idade.

Concernente ao biênio de maior elevação - 2016 a 2017 - na quantidade das publicações relativa às DCNEI (BRASIL, 2009) identificadas por este mapeamento, semelhante à hipótese de Santos, Barroso e Nascimento (2020, p.359), atribuímos o fato às discussões e posterior aprovação da Base Nacional Comum Curricular (BRASIL, 2017).

Quando considerado o número de pesquisas (nove) que se repetem nos bancos de dados supraditos, portanto, foram contabilizados duas vezes no compute geral de trabalhos localizados (28), essa soma recai para 21. A 
seguir, o Quadro 2 apresenta a quantidade de trabalhos duplicadas por plataforma e ano:

Quadro 2 - Trabalhos que versam sobre as DCNEI (BRASIL, 2009) publicados, por ano, em mais de um banco de dados no decénio de 2010 a 2020

\begin{tabular}{|c|c|c|c|}
\hline \multirow[b]{2}{*}{$\begin{array}{c}\text { Ano de } \\
\text { publicação }\end{array}$} & \multicolumn{3}{|c|}{ Quantidade de pesquisas } \\
\hline & $\begin{array}{c}\text { Google } \\
\text { Acadêmico } \\
\text { e } \\
\text { Catálogo de Teses } \\
\text { e Dissertações - } \\
\text { CAPES }\end{array}$ & $\begin{array}{c}\text { Google Acadêmico } \\
\text { e } \\
\text { ResearchGate }\end{array}$ & $\begin{array}{l}\text { Total } \\
\text { por ano }\end{array}$ \\
\hline 2010 & - & - & - \\
\hline 2011 & - & - & - \\
\hline 2012 & - & - & - \\
\hline 2013 & 1 & - & 1 \\
\hline 2014 & - & 1 & 1 \\
\hline 2015 & - & 1 & 1 \\
\hline 2016 & - & 1 & 1 \\
\hline 2017 & 2 & 1 & 3 \\
\hline 2018 & - & - & - \\
\hline 2019 & - & - & - \\
\hline 2020 & - & 2 & 2 \\
\hline Total Geral & 03 & 06 & 09 \\
\hline
\end{tabular}

Fonte: Elaboração das autoras, 2021.

Ao todo, foram encontrados nove trabalhos duplicados: seis se repetiam nas plataformas Google Acadêmico e ResearchGate e três nos sites do Google Acadêmico e do Banco de Teses e Dissertações da CAPES. Tratam-se de seis artigos - Angotti (2014), Carvalho (2015), Ciardellaé (2016), Ostetto (2017), Persicheto e Perez (2020) e Nunes e Gonçalves (2020); duas dissertações - Oliveira (2013) e NUNES (2017) e uma tese - SOUZA (2017).

Quanto ao tipo de publicação, foram localizados dois anais de evento, quinze artigos, um capítulo de livro, oito dissertações, um livro, quatro monografias, cinco Trabalhos de Conclusão de Curso (TCC) e uma tese, conforme indica o Gráfico 2 a seguir: 
Gráfico 2 - Produção acadêmica, por tipo de publicação, sobre as DCNEl (BRASIL, 2009) na década de 2009 - 2020

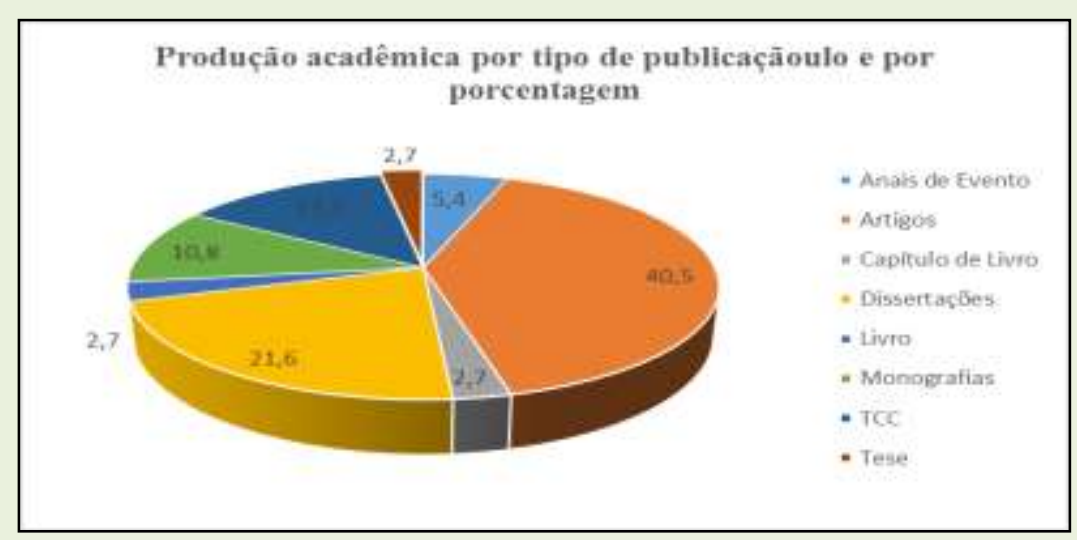

Fonte: Elaboração das autoras, 2021.

O maior percentual de publicações se concentra nas regiões Sul e Sudeste $(77,2 \%)$, sendo 07 dissertações, 01 tese, 10 artigos, 01 capítulo de livro, 01 livro, 06 trabalhos publicados em anais e/ou apresentados em eventos e 08 TCC e monografias. Por outro lado, o menor percentual de trabalhos foi identificado nas regiões Norte, Nordeste e Centro-Oeste $(22,7 \%)$, composto por 02 dissertações, 04 artigos e 04 TCC e monografias. O Gráfico 3 indica essa concentração de trabalhos nos eixos sul e sudeste do país:

Gráfico 3 - Produção acadêmica sobre as DCNEl (BRASIL, 2009) na década de 2009 - 2020 por região do país

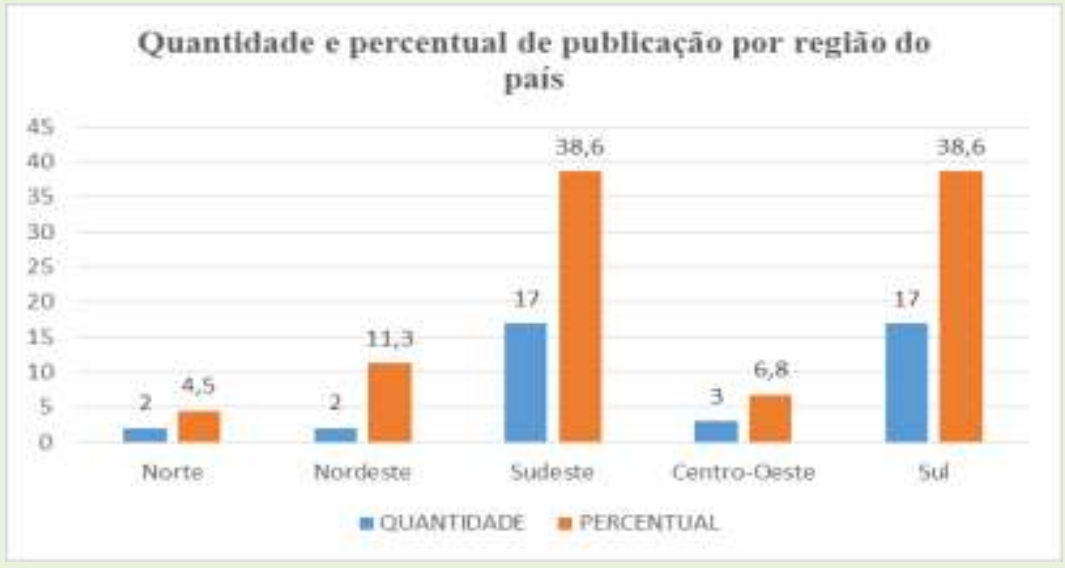

Fonte: Elaboração das autoras, 2021.

A acentuada disparidade entre a quantidade de pesquisas produzidas nos eixos sul/sudeste e norte/nordeste/centro-oeste do país tem sido 
denunciada por diversos estudiosos que a relacionam com "as acentuadas disparidades na distribuição dos recursos científicos e tecnológicos e pela maior disponibilidade de recursos humanos e financeiros devido a políticas implementadas por importantes agências de fomento" (SIDON; HADDAD; MENA-CHALCO, 2016, p.p.22-23).

De forma semelhante, destacam Nazareno e Herbetta (2019, p.104):

a formação da pós-graduação no país é baseada na noção de assimetria, especialmente no que se refere ao investimento em alguns poucos centros de excelência, localizados em centros de poder político e econômico, desenvolvendo espaços elitistas e hierárquicos, assim como faz crescer as assimetrias regionais, tornando desiguais o acesso e a produção de conhecimento entre os distintos espaços de cada região.

Indubitavelmente, a disparidade de recursos de toda ordem bem como a assimetria hierárquica na produção de conhecimento e o acesso desigual a ele nas diferentes regiões e estados brasileiros também se refletem nesse levantamento sobre as pesquisas publicadas no decênio de 2009 a 2020.

Ao analisar os objetivos de cada pesquisa que compõe o conjunto de produção resultante desse levantamento, foram identificados, em conformidade com a Figura 1, posteriormente apresentada, os principais termos referentes às DCNEI (BRASIL, 2009) presentes em seus objetivos. Na referida imagem, os vocábulos que aparecem em frequência máxima e mínima estão grafados em tamanho maior e menor, respectivamente. 
Figura 1 - Nuvem de palavras com os principais termos referentes às DCNEl (BRASIL, 2009) presentes nos objetivos gerais das pesquisas localizadas na década de 2010 a 2020

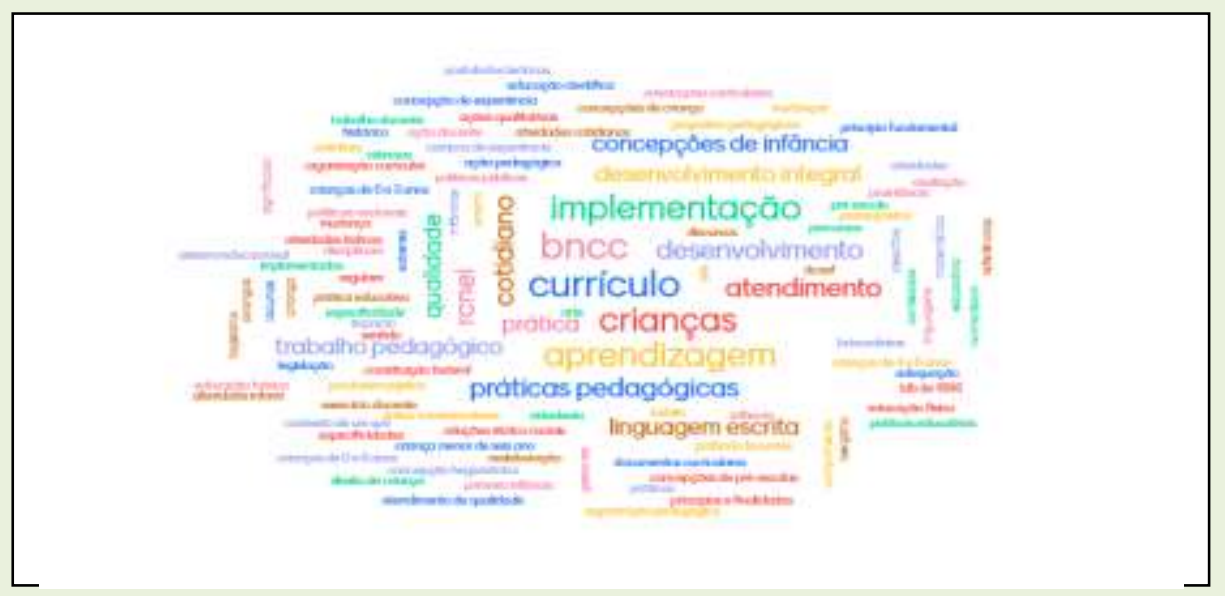

Elaboração das autoras, 2021.

Fonte:

Pelo exposto na Figura 1, foram vários os principais termos e expressões identificados no objetivo geral de cada pesquisa sobre as DCNEI (BRASIL, 2009) incluída nesse mapeamento. As palavras que apresentaram maior frequência foram: criança (11)6, BNCC (06), currículo (06), práticas pedagógicas/ educativas/docentes (06), implementação/ implementada (05), cotidiano (04) e aprendizagem (04). Por seu turno, relações étnicoraciais, berçário, alteridade infantil e direito da criança foram as palavras e expressões de menor constância, sendo citadas apenas uma vez.

No que se refere a esse quantitativo ínfimo (uma citação!) de termos e expressões identificados nos objetivos gerais dos textos, esse resultado coaduna com as reflexões decorrentes dos levantamentos realizados por outros investigadores que se ocuparam dessas temáticas quase invisíveis nos resultados aqui apresentados. Igualmente, indica o que é considerado valioso pesquisar e publicar acerca das DCNEI (BRASIL, 2009) e o que é considerado menos importante, marginal nas investigações sobre este documento.

6 O numeral entre parênteses indica a frequência com que foi citada a palavra ou expressão. 
No que concerne ao tema relações étnico-raciais, por exemplo, embora as pesquisas sobre este assunto venham se ampliando na produção acadêmica brasileira, mormente, por meio de dissertações e teses, desde a década de 2000 a 2010 (SANTOS; SILVA; COELHO, 2014), em estudo realizado por Alves, Barbosa e Ribeiro, (2016), acerca dos projetos políticopedagógicos das instituições educacionais em Goiás, foi constatado que a despeito da

ênfase no papel da Educação Infantil no combate político e pedagógico das discriminações [...] persistem desafios conceituais e operacionais para a materialização da legislação, abarcando acesso, formação de professores, produção e divulgação de materiais pedagógicos [aumento e socialização das pesquisas sobre o tema] e, sobretudo, superação de concepções racistas e preconceituosas presentes na sociedade brasileira (p.312, grifos nossos).

Por seu turno, Silva (2019), ao visar apreender como e com que frequência a formação de professores de Educação Infantil/Educação Básica para o trabalho com o tema Relações Étnico-Raciais-RER, no período de 2003 a 2017, vem sendo discutida nas publicações acadêmicas, identificou a irrisória presença da temática nos trabalhos que localizou.

Aliás, muitos trabalhos do tipo "Estado da Arte" vieram a confirmar nossa hipótese de que RER encontram forte resistência para ser inserida nos currículos e ementas das disciplinas dos cursos de Pedagogia. O mesmo se dá nas investigações científicas: o foco nesse tema tem sido pouco frequente, particularmente, naquelas que se referem à formação universitária de professores que exercem a docência na Educação Infantil, congruente ao que afirma Silva (2019, p.73, grifos nossos):

esse assunto [RER] é pouco visibilizado nas pesquisas educacionais, especialmente, aquelas que se referem à formação inicial docente. Vale destacar que nenhum dos trabalhos citados revelou preocupação especial com a atuação docente na Educação Infantil. (SILVA, 2019, p.73, grifos nossos).

De forma similar, é emblemática da ausência das palavras e expressões "bebês e sua educação formal", incluindo aí, o vocábulo "berçário", naquilo que é considerado mais importante, primordial e 
recorrente nas investigações sobre currículo, enfocando as DCNEI (BRASIL, 2009). O resultado do estudo realizado por Gobbato e Barbosa (2017, p.32, grifos nossos) atesta que:

Se, por uma lado, eles [os bebês] estão mais perto, dentro das unidades de educação infantil; por outro, as análises e as reflexões feitas nesse trabalho mostram que ainda estão tão longe: ingressam nas instituições cada vez mais cedo, mas estão mais ausentes do que presentes nos discursos, nos documento e nas pesquisas.

Atrelados aos termos de maior e menor recorrência no objetivo geral de cada publicação, os verbos mais referidos foram: discutir (08), investigar (08), compreender (06) e analisar (06). Considerando a Taxonomia de Bloom, os verbos supraditos, pertencem às seguintes categorias: compreensão, que diz respeito à "capacidade de entender a informação ou fato, de captar seu significado e de utilizá-la em contextos diferentes" (FERRAZ; BELHOT, P.426) - é o caso dos verbos discutir e compreender; e análise, que corresponde à "identificação das partes, análise de relacionamento entre as partes e reconhecimento dos princípios organizacionais envolvidos. Identificar partes e suas inter-relações" (FERRAZ; BELHOT, P.426) - aqui se inserem os verbos analisar e investigar.

A identificação das palavras que mais e menos figuraram no objetivo geral dos textos bem como os verbos a elas relacionados possibilitou delimitar os temas abordados pelos trabalhos sobre as DCNEI (BRASIL, 2009) localizados na década focalizada nesse artigo, conforme aponta o Quadro 3:

Quadro 3 - Temas abordados pelas publicações sobre as DCNEI (BRASIL, 2009) localizadas no decénio enfocado

\begin{tabular}{|l|c|}
\hline \multicolumn{1}{|c|}{ TEMA } & N$^{\circ}$ DE PESQUISAS \\
\hline $\begin{array}{l}\text { Conceitos / Análises do documento/ Propostas das } \\
\text { DCNEI/ Políticas/Teoria/ Concepções }\end{array}$ & 25 \\
\hline Brincadeiras & 2 \\
\hline Educação Física & 2 \\
\hline Temas transversais (Educação ambiental/educação & 3 \\
\hline
\end{tabular}




\begin{tabular}{|l|c|}
\hline étnico racial/Gênero) & 3 \\
\hline Áreas de conhecimento (Ciências, Lingua Escrita e & 3 \\
Arte) & 7 \\
\hline Qualidade & 6 \\
\hline Práticas (implementação/repercussões) & 1 \\
\hline DCNEl e BNCC & 1 \\
\hline Avaliação da aprendizagem & 2 \\
\hline Datas comemorativas & 1 \\
\hline Prática com bebês & $\mathbf{5 6}$ \\
\hline Transição Educação Infantil e Ensino Fundamental & \\
\hline Total & \\
\hline
\end{tabular}

Fonte: Elaboração das autoras, 2021.

A análise dos dados apresentados no Quadro 3 permite afirmar que o interesse por temas mais conceituais (Conceitos / Análises do documento/ Propostas das DCNEl/ Políticas/Teoria/ Concepções), com 25 referências nas pesquisas, estiveram no centro dos interesses. Essa constatação nos permite inferir que na década privilegiada por este artigo, os estudiosos pareciam mais preocupados em compreender o documento e a concepção de currículo nele presente. Daí, a diminuta presença do assunto "brincadeira" (apenas duas investigações a tiveram como interesse central) e total ausência do assunto "interações", eixos norteadores das práticas pedagógicas na Educação Infantil (DCNEl, 2009).

O segundo tema mais recorrente foram as práticas (07). Essa relativa concentração nesse componente da docência em Educação Infantil confirma o que estudiosos, desde o final da década dos anos 90 , vinham apontando em seus levantamentos: mesmo havendo certo consenso entre muitos professores e pesquisadores e alguns políticos e gestores institucionais, sobre a função de cuidado/educação na Educação Infantil, "o mesmo não acontece em relação à definição do que isso significa e de como deve ser viabilizada essa possibilidade junto às crianças" (ROCHA, 1999, p.15).

A BNCC (BRASIL, 2017) aparece associada às DCNEI (BRASIL, 2009) em seis publicações, o que pode estar relacionado ao contexto de elaboração, discussão e aprovação desse outro importante documento mandatório, a 
BNCC (BRASIL, 2017), cujas DCNEI (BRASIL, 2009) se constituíram em um dos principais aportes legais de sustentação.

Verifica-se, também, que temas ainda pouco consensuais como "sexualidade", "presença masculina de professores na Educação Infantil" e "Educação Ambiental", não figuram entre os temas abordados pelas publicações ou aparecem apenas uma vez, como "Avaliação", "Transição Educação Infantil" e "Datas comemorativas".

\section{O BALANÇO DE UMA DÉCADA DA PROMULGAÇÃO DAS DCNEI: DESAFIOS E POSSIBILIDADES DE PESQUISA}

O objetivo desse texto foi apresentar um balanço do que foi produzido em trabalhos científicos na área da Educação Infantil na primeira década após a promulgação das DCNEI (BRASIL, 2009).

Considerando o recorte temporal (o primeiro decênio após a promulgação das DCNEI), bem como o quantitativo de pesquisas encontradas nesse levantamento e as bases de dados consultadas, os trabalhos que compõem o corpus desse artigo evidenciam inúmeros desafios que precisam ser enfrentados pela comunidade acadêmicocientífica em relação ao currículo na Educação Infantil e suas especificidades, o que possibilita a ampliação dos debates sobre o tema.

É fato que a dimensão do currículo da Educação Infantil é mais complexa quando comparada às demais etapas da educação básica, uma vez que há inúmeros fatores envolvidos, tais como as peculiaridades ligadas ao processo de desenvolvimento das crianças e as especificidades que precisam ser consideradas na práxis pedagógica, envolvendo uma maior aproximação com as famílias e as funções indissociáveis de cuidar/educar (OLIVEIRA-FORMOSINHO, 2001).

Os trabalhos aqui reunidos apontam os temas de maior destaque nas pesquisas e que envolvem a compreensão de currículo em sua episteme, perpassando por reflexões acerca das teorias, concepções e conceitos que o compõem. Em contrapartida, assuntos como o brincar, a avaliação e a 
prática com bebês, fundamentais para a efetivação de um currículo que considere a criança como centro, ainda são pouco explorados.

A aprovação da BNCC (BRASIL, 2017), em 2017, acirrou as discussões em torno do currículo que passa ser organizado através de "campos de experiências", que abarcam as diversas dimensões do conhecimento, não podendo ser compreendidos na acepção de uma trajetória linear, cuja avaliação pressupõe produtos finais, mas como uma forma curricular a ser constituída "[...] pelos diferentes percursos narrativos das experiências que acontecem no encontro cotidiano" (PASUCH; FRANCO, 2017, p. 383) de crianças e adultos no contexto de creches e pré-escolas.

À guisa de conclusão, podemos perceber os avanços legais (ou, no mínimo, esforços nessa direção!) relativos à definição de um currículo desenvolvente (DAVIDOV, 1988) para as creches e pré-escolas brasileiras. Contudo, não podemos negar as ausências e inconsistências nas discussões em torno do tema, o que impulsiona a necessidade da realização de mais pesquisas nesse caminho.

\section{REFERÊNCIAS}

ALVES, N. N. de; BARBOSA, I. G.; BARBOSA, R. N. S. Educação para as relações étnico-raciais na educação infantil em documentos nacionais.

Revista Contemporânea de Educação, vol. 11, n. 22, ago/dez de 2016.

ANDRÉ, M. E. D. A. A produção acadêmica sobre formação de professores: um estudo comparativo das dissertações e teses defendidas nos anos 1990 e 2000. Formação Docente - Revista Brasileira de Pesquisa sobre Formação de Professores, v. 1, n. 1, p. 41-56, 9 maio 2009.

BRASIL. Constituição da República Federativa do Brasil. São Paulo: Imprensa Oficial do Estado, 1988.

BRASIL. Estatuto da Criança e do Adolescente. Lei n. ${ }^{\circ} 8.069 / 90$, de 13 de julho de 1990. São Paulo: CBIA-SP, 1991.

BRASIL. Lei de Diretrizes e Bases da Educação Nacional. Lei n. ${ }^{\circ} 9.394 / 96$, de 20 de dezembro de 1996. 
BRASIL. Ministério da Educação e do Desporto. Secretaria da Educação Fundamental. Referenciais curriculares nacionais para a Educação Infantil. Brasília: MEC/SEF, v1, 1998.

BRASIL. Presidência da República. LEI N 12.796, DE 4 DE ABRIL DE 2013. Altera a Lei n 9.394, de 20 de dezembro de 1996, que estabelece as diretrizes e bases da educação nacional, para dispor sobre a formação dos profissionais da educação e dar outras providências. Brasília. 2013.

BRASIL. Ministério da Educação. Base Nacional Comum Curricular. Brasília, 2017.

BRASIL. Coordenação de Aperfeiçoamento de Pessoal de Nível Superior. Portaria n. 13, 15 de fevereiro de 2006. Institui a divulgação digital das teses e dissertações produzidas pelos programas de doutorado e mestrado reconhecidos. Disponível em:

<http://www.capes.gov.br/images/stories/download/legislacao/Portaria_013 _2006.pdf>. Acesso em: 10 de ago. 2021.

CAREGNATO, S. E. Google Acadêmico como ferramenta para os estudos de citações: Avaliação da Precisão das Buscas por Autor. Ponto de Acesso, v. 5 , n. 3, p. 72-86, 2012.

La, R. Saballa de; FOCHI, P. S. Pedagogia do cotidiano: reivindicações do currículo para a formação de professores. Em Aberto, Brasília, v. 30, n. 100, p. 23-42, set./dez. 2017.

DAVIDOV, V. La enseñanza escolar y el desarrollo psíquico. Moscú: Editora Progresso, 1998.

EVEN3 PUBLICAÇÕES. Google Acadêmico: como acessar, pesquisar e depositar artigos. Disponível em: https://blog.even3.com.br/googleacademico-como-usar/Acesso em: 11 ago. 2021.

FARIA, L. I. L. et al. Análise da produção científica a partir de publicações em periódicos especializados. In: FAPESP. Indicadores de ciência, tecnologia e inovação em São Paulo -

2010. São Paulo: FAPESP, 2011.

FERRAZ, A.P.C.M.; BELHOT, R.V. Taxonomia de Bloom: revisão teórica e apresentação das adequações do instrumento para definição de objetivos instrucionais. Gest. Prod. São Carlos, v. 17, n. 2, p. 421-431, 2010. Disponível em: < http://www.scielo.br/scielo.php?pid=S0104530X2010000200015\&script=sci_abstract\&tlng=pt> Acesso em 17 jul. 2021.

FERREIRA, N. S. de A. As pesquisas denominadas "estado da arte". Educação e Sociedade, São Paulo, ano 23, n. 79, p.257-272, ago. 2002. 
FOCHI, P. S. A complexa sutileza da ação pedagógica com bebês. In: PEREIRA, Ana Cristina Carvalho (org.). Atravessamentos: Ensino -

Aprendizagem de arte, formação do professor e educação infantil. Escola de Belas Artes. UFMG, 2015.

GOBBATO, C.; BARBOSA, M. C. S. A (dupla) invisibilidade dos bebês e das crianças bem pequenas na educação infantil: tão perto, tão longe. Revista Humanidades e Inovação, v. 4, n. 1, p. 21- 36, 2017. Disponível em: https://revista.unitins.br/index.php/humanidadeseinovacao/article/view/289. Acesso em: 01 dez. 2019.

KRAMER, S. Profissionais de Educação Infantil: gestão e formação. São Paulo: Ática, 2005.

LEONTIEV, A. O desenvolvimento do psiquismo (O homem e a cultura). Lisboa: Horizonte, 1978.

LOPES, A.M. D'Ávila. A era dos direitos de Bobbio: entre a historicidade e a atemporalidade. Revista de Informação Legislativa, Brasília a. 48 n. 192, v. 192, p. 7-19, out./dez. 2011.

NAZARENO, E.; HERBETTA, A. F. A pós-graduação brasileira: sua construção assimétrica e algumas tentativas de superação. Estudos de Psicologia (Natal. Online), v. 24, p. 103-112, 2019. Disponível em:

http://pepsic.bvsalud.org/pdf/epsic/v24n2/a02v24n2.pdfAcesso em: 10 de ago. 2021.

OLIVEIRA, Z. de M. R. O currículo na educação infantil: o que propõem as novas diretrizes nacionais? Anais do I seminário nacional: currículo em movimento - Perspectivas Atuais. Belo Horizonte, novembro de 2010.

Disponível em http://portal.mec.gov.br/docman/dezembro-2010-pdf/7153-21-curriculo-educacao-infantil-zilma-moraes/file. Acesso em 23 de outubro de 2018.

OLIVEIRA-FORMOSINHO, J. A profissionalidade específica da educação de infância e os estilos de interacção adulto/criança. In: OLIVEIRAFORMOSINHO, Julia e FORMOSINHO, João (orgs), Associação crianças: um contexto de formação em contexto. Braga: Coleção Minho. São Paulo, 2001.

PASUCH, J.; FRANCO, C. P. O currículo narrativo na educação infantil das crianças do campo: reflexões para um diálogo pedagógico. Cadernos CEDES, Campinas, v. 37, n. 103, p. 377-392, dez. 2017.

RAMOS, B. B. A obrigatoriedade de matrícula na educação infantil: repercussões para a identidade da pré-escola da rede pública municipal de ensino de Fortaleza - 2019. (Projeto de Pesquisa de Mestrado). Universidade 
Federal do Ceará, Faculdade de Educação, Programa de Pós-graduação em Educação, Fortaleza, 2019.

RESENDE, E. dos S. Fontes de informação para a pesquisa em educação. XXVIII Congresso Brasileiro de Biblioteconomia e Documentação. v. 28 (2019): XXVIII CBBD, Vitória - ES, 01 a 04 de outubro de 2019. (Anais)

RIBEIRO, A. G. A influência da formação inicial universitária no curso de Pedagogia da FACED/UFC para as práticas de cuidado/educação na creche - 2020. Dissertação (mestrado). Universidade Federal do Ceará, Faculdade de Educação, Programa de Pós-Graduação em Educação, Fortaleza, 2020.

ROMANOWSKI, J.; PAULIN; TEODORA ENS, R. As pesquisas denominadas do tipo "estado da arte" em educação. Revista Diálogo Educacional, [S.I.], v. 6, n. 19, p. p. 37-50, jul. 2006. ISSN 1981-416X. Disponível em: $<$ https://periodicos.pucpr.br/index.php/dialogoeducacional/article/view/241 76>. Acesso em: 11 ago. 2021.

ROSEMBERG, F. Educação Infantil, gênero e raça. In.: GUIMARÃES, A. S. A.; HUNTLEY, L. (Orgs.). Tirando a máscara: ensaios sobre o racismo no Brasil. São Paulo: Paz e Terra, 2000.

SANTOS, S. V. S. dos; BARROSO, F. P.; NASCIMENTO, J. M. Convergências e tensões na produção acadêmica sobre currículo da Educação Infantil.

Revista e-Curriculum, São Paulo, v.18, n.1, p.350-371 jan./mar. 2020.

SANTOS, R. A. dos; SILVA, R. M. de N. B; COELHO, W. de N. B. (2016).

Educação e relações raciais: estado da arte em programas de Pós-

graduação em Educação (2000-2010). Revista Exitus, v.04, n.1, Jan/Jun. 2014, p. 111-141. Disponível em:

http://www.ufopa.edu.br/portaldeperiodicos/index.php/revistaexitus/article/ view/132/132 Acesso em: 10 de ago. 2021.

SIDONE, O. J. G.; HADDAD, E. A.; MENA-CHALCO, J. P. A ciência nas regiões brasileiras: evolução da produção e das redes de colaboração científica.

TransInformação, Campinas, v.28, n.1, p.15-31, jan./abri. 2016.

SILVA, B. R. M. Educação Infantil e relações étnico-raciais Contribuições do curso de Pedagogia para a formação inicial docente / Bárbara Rainara Maia Silva. - 2019. (Projeto de Pesquisa de Mestrado). Universidade Federal do Ceará, Faculdade de Educação, Programa de Pós-graduação em Educação, Fortaleza, 2019.

Vigotski, L. S. Psicologia Pedagógica. Trad. Paulo Bezerra. $3^{a}$ ed. São Paulo: Martins Fontes, 2010. 
ZABALZA, M. Os dez aspectos-chave de uma educação Infantil de qualidade. In: 1998. Qualidade em Educação Infantil. Porto Alegre: Artmed,

Recebido em: 04 de agosto de 2021. Aprovado em: 30 de agosto de 2021. Publicado em: 24 de setembro de 2021. (c) (1) 